\title{
What Could be the Future of Mining?
}

\author{
Jean François Geneste* \\ CEO of WARPA, France
}

\begin{abstract}
We show that mining is a compulsory activity for humankind which caused what is known as the industrial revolution and allowed dramatic improvement of the human way of life. Today, many mines are inaccessible because there is no road for reaching them. We set up the requirements needed to disenclave them and propose an airship program which would allow reaching all the mines on the planet. Finally, we evoke mining on asteroids since one of the major technical problems encountered is of the same nature as one which has already been solved for the airship.
\end{abstract}

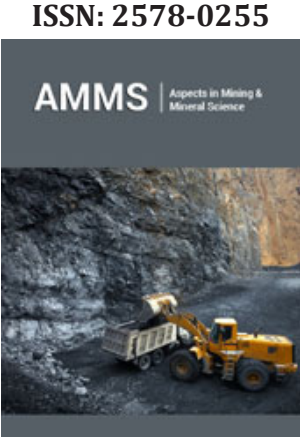

*Corresponding author: Jean François Geneste, CEO of WARPA, 30 chemin Boudou, 31200 Toulouse, France

Submission: 価 March 06, 2020

Published: 眥 March 18, 2020

Volume 4 - Issue 4

How to cite this article: Jean François Geneste. What Could be the Future of Mining?. Aspects Min Miner Sci.4(4). AMMS.000595.2020.

DOI: 10.31031/AMMS.2020.04.000595

Copyright@ Jean François Geneste, This article is distributed under the terms of the Creative Commons Attribution 4.0 International License, which permits unrestricted use and redistribution provided that the original author and source are credited.
Keywords: Mining; Recycling; Energy; WARPA

\section{Introduction}

The world is populated with about 7.5 billion of persons and its growth should reach about 10 billion soon. If we want to provide the same mean standard of life to this population, we shall need raw resources. We should be conscious however of the following. Until the middle of the $19^{\text {th }}$ century, man on earth was dependent on the natural cycles because he relied only on "renewable" power sources such as wood and agriculture. The breakthrough of the $19^{\text {th }}$ century was the ability to extract substantial amounts of energy from the underground. It began with coal and then turned to oil and gas, mainly. The invention of the engine allowed also huge increase in the extraction of raw materials and allowed, at least for the so-called western countries, quick development. Today, with the growing population and the huge increase in consumption, some voices raise saying that we could be short of resources. This is how the notion of peak oil was born and we might have a peak in any resource, for example there are clues that we could have some shortage in the indium production worldwide whereas it is an essential component of our electronic devices. One obvious solution for solving the problem is recycling. But this is no panacea as we shall prove it next. So, in a first period, we shall propose a specific means to explore new deposits which are unavailable today. Finally, we shall quickly say a word about asteroid mining as the next horizon after the much shorter-term solution we shall describe in part 3.

\section{The Limits of Recycling}

The main idea of recycling is to sort out waste and collect what can be transformed again and as such save raw materials, leading to a drop in the demand of extraction from the ground. This is the case of iron for example. The process of recycling iron is well known, and it is not our intention here to give the different methods which are at use. We just will look at this process globally and will point out its weaknesses. There are in fact 2 weaknesses. The first one, which is not the major one, is that the collection of waste cannot be $100 \%$ efficient. There are necessary losses in this process. And, at the world level, we can see that as a purely entropic process [1], spreading raw matter around the world. This will ultimately bring to the exhaustion of the resource since production in such a context can be seen as an anti-entropic scheme and therefore needs energy consumption. We can have a clue of this already in the extraction process. Indeed, the best deposits, for a given depth, have been exploited already [2]. Only less concentrated (i.e. more entropic) deposits remain. And for waste, this is exactly the same process. The big sources of waste have already been identified, and it remains diffuse sources which are much more difficult to treat. There is, in addition, a technological trend which grows with the increase in the quality of engineering we perform. Indeed, since we have invented the computer, we are able to optimize. The consequence of optimization is the decrease to some extent of the use of raw materials for a given function, but also the design of 
the optimum mix of raw materials, for example through the making of alloys, so that this deeply increases the global entropy of waste and makes their recycling potentially more expensive.

The second weakness of the recycling, the major one today, is the fact that it needs energy consumption and energy today, worldwide, is coming from mining, whatever it is: coal, oil, gas, uranium [3]. So, mining is kind of a curse for humankind be long as it needs energy out of its underground (an alternative with might be fusion, but this is not for tomorrow). And we can see some kind of world race to energy resources, for example in the arctic for oil deposit exploitation. We shall therefore conclude from this subparagraph that we absolutely need to mine on and that despite recycling, we shall absolutely need to continue mining raw materials be they energetic or not. The only brake which could be put on this would be the mastering of transmutation of matter, but like fusion, this is not for tomorrow.

\section{Reaching Today Inaccessible Resources}

\section{Generalities}

The fact is that today, on earth, there are inaccessible resources. What do we mean by "inaccessible"? In fact, if we consider for example Canada, there are about 2500 mines [4] which cannot open, because there is no road bringing to them. More exactly, the expected time for the building of such roads is greater than 30 years, which simply means never in industrial terms [4]. Moreover, such roads, if they existed, would involve huge cost, simply because the climatic conditions there, are very severe and imply huge maintenance for such road and therefore high cost and Canada is far from being the only country concerned by this. There are of course and obviously all northern countries such as Russia, Norway, Finland, Sweden, but not only the northern countries are concerned. The equatorial ones also such as Brazil, the Democratic Republic of Congo and so on. The preceding might seem to be obvious, but it was worth being written because we can deduct from this some conclusion: the surface at stake which we cannot yet explore and exploit is huge and lets us think that we still have huge reserves and this allows to kill the very widespread idea among young people today that we are exhausting the planet. This is far from being the case!

\section{What do we need?}

In fact, it depends on the kind of resource we want to extract. Let us concentrate on low weight, high value stuff like diamonds for example. And to fix things without any loss of generality, let us consider we would target a mine in the deep Canadian north. What do we need? First of all, we need to provide the extraction means on site: the extraction machines, the men, their buildings, etc. We also need to bring the treatment machines for this light weight, high value stuff. And finally, we need to bring back the raw treated material back to civilization. But how to bring them in and from remote, roadless fields? We clearly need a device which can transport heavy loads on a regular basis, whatever the weather, safely, quickly, in a cheap way. Can we afford this? Yes, just read next paragraph.

\section{The solution}

The idea is a heavy load transportation airship. Its main characteristics must be

1. All-weather

2. $\quad$ All-terrain

3. No hangar

4. A drone

5. Filled with hydrogen

6. Zero-emission

7. Low cost (both for the purchase and exploitation)

8. Very reliable

9. Very safe

Let us come and justify all these characteristics one by one. The all-weather condition is obvious if you want to get availability. Technically, it implies a specific structure which can resist storms and an overdesigned propulsion (Figure 1). The all-terrain is as much desirable of course since we cannot afford having to bring any pre-installation for landing and taking off. No airship in the world today has such essential property [5]. The no hangar feature is also compulsory and in the deep north conditions is more or less linked to the all-weather requirement. Nevertheless, this is more than this. This means that maintenance can be done anywhere in any conditions. It also means that the airship can be "stored" for long periods wherever it is, with no risk of damage. In addition, this dramatically lowers down the ownership cost. The dronization of the device while not compulsory is essential simply because the exploitation cost, in case of a pilot on board, will essentially be the pilot cost. If we want a cheap device, this implies dronization. This is easy to achieve since, unlike a plane or a helicopter, a failure never triggers any crash. Hydrogen now is a requirement because of cost. It is 10 times cheaper than helium and can be produced anywhere in the world. The problem is to manage safety of such devices. We know how to do this. The zero-emission requirement is the cherry of the cake. If we consume hydrogen, then we shall be zero-emission. For the remaining requirements, they are standard and obvious. Now, WARPA has developed such a concept which has all the above features. Unexpectedly, this is not any cigar shaped airship, but a catamaran. Please look at the picture hereunder. The goal of this paper is not to give technical details about this device, but some relevant ones to prove the mining community of its interest. There is a whole family of products with respective payloads 10t, 100t, 500t, 1000t. The development program can start with 100 t directly with no risk. In such a case, the cost of transportation is $0.02 € / \mathrm{t} . \mathrm{km}$, which is much cheaper than any truck [4]. The availability of the airship is 360 days a year 24 hours per day. In the development, the first flight is on year 2 and a ready to commercially fly on year 3 [4]. Therefore, we have cut the expected time to reach the mines with some means by a factor of 10 and 3 years is quite an acceptable schedule. 


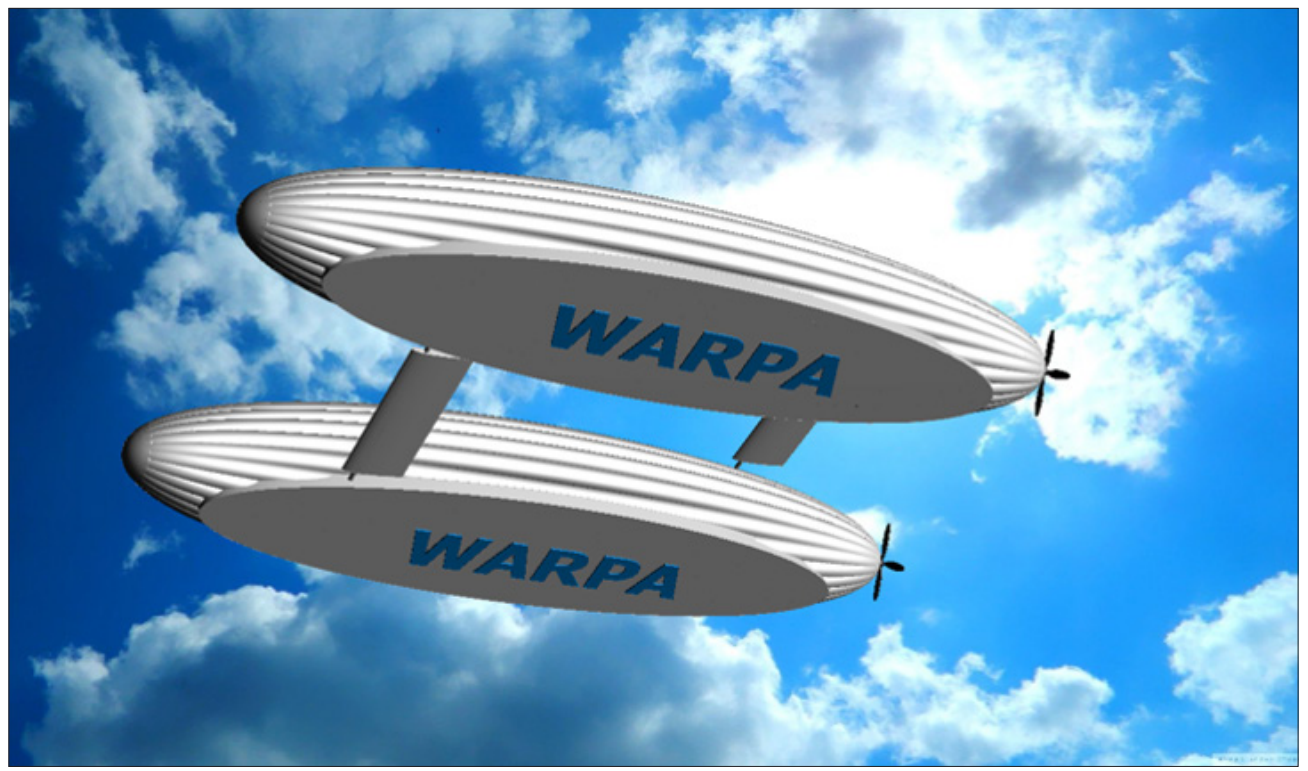

Figure 1: Warpa's catamaran airship.

\section{Mining in space}

This idea was born not so long ago in the USA, because with there, people have thought about how to make space profitable. The basic idea is to mine asteroids which would be made, mainly of precious materials. There are however 2 big impediments for such exploitation plus a third one which we will discuss after. Let us begin with the technical ones. The first one is obviously the cost of launch and of spacecrafts. Nevertheless, Space X between 2002 and now, was able to cut the price of the kilogram in orbit by a factor of 4 . We think at WARPA, that this can be improved by an additional factor of 10 , which would bring the cost of the kilogram in orbit at $500 €$. Now, reaching a Low Earth Orbit (LEO) or Ground Transfer Orbit (GTO) is not enough to reach asteroids in general. We therefore need additional propulsion means. These means are characterized by what we call the specific impulse, and which represents the amount of needed fuel in order to accelerate. The unit of the specific impulse is in seconds. Traditional chemical propulsion is between 300 and 400s [6]. Electric propulsion is about 1500s [6]. The problem with this latter technology is that the price to pay is time. To go far, you need much more time than with chemical propulsion, but for launch costs, your spacecraft is much lighter. Now, WARPA has designed an infinite the word impulse space propulsion engine which definitely rules out the problem. It therefore remains the launch costs.

The second technical problem is landing on an asteroid. In fact, landing is not enough. Indeed, once you have landed, you need to drill! But drilling implies being tethered to the asteroid because there, your weight is nearly zero. Warpa has developed some original concept which allows this. Indeed, the problem of landing an airship is the with one of landing a device which has some mass but zero weight. This is exactly the same for a space probe which needs to land on an asteroid. Let us finally tackle the third problem which is purely human. In theory at least, it is forbidden to bring back raw materials from space. They would belong to humankind in general. The USA have passed a law avoiding this, but it not sure that it is internationally legal. Let us expect that the law will change soon when this kind of activity becomes affordable and this is for soon.

\section{Conclusion}

We have proved a few things in this paper.

1. Recycling will not cancel the necessity to keep on mining

2. We have listed the requirements for mining in remote roadless places

3. We have proposed a specific concept of an airship fulfilling all the requirement

4. We have proved that asteroid mining is possible for reasonable cost in the mean term.

\section{References}

1. Greiner, Walter, Neise, Ludwig, Stöcker, et al. (1995) Thermodynamics and statistical mechanics. Springer, Germany.

2. Renardet P (2004) Geopolitics of energy, Ellipses.

3. https://www.connaissancedesenergies.org/fiche-pedagogique/ chiffres-cles-production-d-energie

4. (2017) WARPA, Airship Business Plan.

5. (2015) WARPA, Characteristics of airships worldwide.

6. Maral G, Bousquet M (2002) Satellite Communications Systems, John Wiley \& Son Ltd, UK. 